Научная статья

УДК 373.29

DOI: $10.18101 / 2307-3330-2021-4-38-44$

\title{
ИСПОЛЬЗОВАНИЕ ЗНАКОВО-СИМВОЛИЧЕСКИХ СРЕДСТВ В ИНТЕЛЛЕКТУАЛЬНОМ РАЗВИТИИ ДОШКОЛЬНИКОВ
}

\section{(C) Власова Нина Васильевна}

доцент, магистр педагогических наук,

Университет Туран-Астана

Казахстан, 010013, г. Нур-Султан, Ыкылас Дукенулы, 29

sher_nina147@mail.ru

\begin{abstract}
Аннотация. В статье приведены характеристики особенностей интеллектуального развития детей дошкольного возраста, показана роль знаково-символической функции мышления в этом процессе, значение этой функции в социализации детей. Дается характеристика системы знаково-символических средств мышления, этапы их освоения дошкольниками. Для этих функций используются такие виды знаково-символической деятельности, как кодирование и декодирование информации, моделирование ситуации, замещение и схематизация среды и других обстоятельств, надлежащих изучению.

Практиков дошкольного образования заинтересуют приведенные в статье некоторые методики выявления у детей уровней освоения знаково-символических средств мышления (способности к моделированию), педагогические технологии формирования способности к моделированию.

Ключевые слова: интеллектуальное развитие, интеллектуальное развитие детей дошкольного возраста, уровни освоения знаково-символических средств мышления, моделирование, социализация, процесс познания, уровни психического отражения: сенсорноперцептивный, уровень представлений и вербально-логический.
\end{abstract}

\section{Для цитирования}

Власова Н. В. Использование знаково-символических средств в интеллектуальном развитии дошкольников // Вестник Бурятского государственного университета. Образование. Личность. Общество. 2021. № 4. С. 38-44.

Проблема интеллектуального развития дошкольника, является актуальной, так как в любой характеристике развития ребенка, в первую очередь отмечаются его интеллектуальные способности и способность к социализации. Интеллектуальное развитие характеризуется специфической формой организации познавательного опыта ребенка, обеспечивающая возможность эффективного взаимодействия с окружающей действительностью.

В современном понимании интеллектуальное развитие оценивается как общая способность к познанию и решению проблем, определяющая успешность в любой деятельности, в особенности в накоплении знаний и успешной социализации.

В психологическом словаре, интеллектуальное развитие определяется как форма поведения, характеризующая вербальный уровень интеллекта (запас слов, эрудицию, умение понимать обращенную к нему речь), способность решать проблемы, практический интеллект (умение добиваться своих целей, в решении возникших проблем) [1].

Изучению интеллектуального развития уделяется большое внимание, при оценке общего развития ребенка. Этот аспект развития изучается в разных психологических 
дисциплинах: в общей, возрастной, инженерной и дифференциальной психологии, патопсихологии и нейропсихологии, в психогенетике. Некоторые аспекты развития интеллекта (структурно-генетический, когнитивистский, факторно-аналитический подход), рассмотрены в работах зарубежных психологов (А. Бине, Ж. Пиаже, Г. Айзенк, Л. Терстоун, Д. Векслер, Р. Кеттелл, Дж. Гилфорд, Ч. Спирмен и др.) [2].

В отечественной психологии XX века исследования интеллекта развивались в нескольких направлениях: изучение психофизиологических задатков общих умственных способностей (Б. М. Теплов, В. Д. Небылицин, Э. А. Голубева, В. М. Русалов), эмоциональной и мотивационной регуляции интеллектуальной деятельности (О. К. Тихомиров), когнитивных стилей (М. А. Холодная). Особого внимания заслуживает разработанный Н. И. Чуприковой принцип дифференциации в умственном развитии, посредством которого объясняется закон умственного развития человека в онтогенезе [3].

В поисках эффективных способов интеллектуального развития, в современных условиях основной упор делается на использование современных методов, направленных на развитие познавательных способностей детей.

Учитывая, что основным содержанием интеллекта являются знания, способы добывания этих знаний и умение решать практические задачи, необходимо определить, каким образом проводить эту работу уже начиная с дошкольного возраста.

Знания формируются на основе представлений об окружающем мире, в виде образов тех предметов, с которыми сталкивается ребенок. В процессе знаний об окружающем, используются все анализаторы, помогающие воспринимать и сохранять их.

По мнению М. А. Холодной, в человеческом мозгу, существуют психологические структуры, обеспечивающие осуществление самых разных процессов, независимо от их конкретного содержания. В качестве довода, она отмечает, что, если бы все знания хранились в виде прямых копий воспринятого, долговременная память должна была бы располагать неограниченным пространством для их хранения. На самом деле, обобщенно-абстрактная форма хранения, во-первых, делает репрезентации более сжатыми и компактными. Во-вторых, их абстрактно-обобщенные «ячейки» оказываются пригодными для анализа и синтеза практически бесконечного множества объектов и событий, так как вычерпываю из текущей информации, соответствующие этим «ячейкам» свойства и отношения [6].

По мнению Л. С. Выготского, процесс социализации происходит в результате овладения различными формами знаков. Вся получаемая человеком информация, подвергается специальной обработке, и запечатлевается в виде знаков и символов этих представлений. Благодаря этой способности, происходит процесс социализации, приобщение человека к многообразию предметов и явлений окружающего мира. В свое время В. Гумбольт обращал внимание, что слово является материальным знаком мысли. Таким образом, этот знак позволяет отделить его от других слов и дает возможность мыслящему человеку воспринимать предметы окружающего мира, обогащать свой словарный запас [4].

Особое освещение получил этот вопрос в работах Э. Кассирера в его представлениях о «духовном формировании» восприятия благодаря его преобразованию, при помощи символов, получая знаковое обозначение.

Присвоение предметам символа, это особая форма придания смысла в преобразовании воспринимаемого образа и выражаемого с помощью этой формы [7]. 
Таким образом, мы подошли к проблеме использования знаково-символических средств в интеллектуальном развитии дошкольников. Именно в периоде дошкольного развития происходит процесс приобщения его к социальному опыту, накопленного предыдущими поколениями, развитие речи, познание предметов и явлений окружающего мира, их названия и свойств. В результате применению знаков и символов ребенок присваивает человеческую культуру, историю, языки социальную среду.

В своем развитии человеческое общество придумало целую систему знаков, которые обеспечили развитие современного общества. Широкое употребление получили вербальные, графические, образно жестовые и другие знаковые системы, в различных областях науки. К ним можно отнести математические, химические знаки, различные формулы в физике и знаковые обозначения в географии, геологии и других науках.

В дошкольном возрасте дети уже активно усваивают знаково-символические обозначения, им доступны словесные, графические, образно-жестовые знаки,

Самыми доступными в дошкольном возрасте являются словесные, графические и образно-жестовые знаки. Посредством знаково-символических средств удается кодировать и декодировать информацию, идентифицировать изображение с реальностью, выделять в моделях закономерности, зафиксированные в них, оперировать моделям. В результате освоения знаково-символических средств, у ребенка формируется способность к знаковому преобразованию предметов окружающего мира, способствует социализации.

Усвоение знаково-символических средств, происходит во всех видах деятельности, в которых участвует ребенок. В тоже время, в ходе использования знаково-символических средств повышается интеллектуальные уровень развития, так как все виды познавательной и предметно-практической деятельности сопровождаются мыслительной деятельностью (В. И. Логинова, П. Г. Саморукова) [8].

Проблема опосредствования психических процессов знаком и символом, обозначена еще Л. С. Выготским. Он рассматривал знак, как образ и как орудие деятельности.

В психологических исследованиях, как теоретических, так и экспериментальных раскрыта сущность формирования предметного образа, при помощи знаково-символической системы процессов познания и выявлены специфические черты (Б. Г. Ананьев, С. В. Кравков, А. Н. Леонтьев, С. Л. Рубинштейн, А. А. Смирнов, Б. М. Теплов и др.).

В работах С. Л. Рубинштейна отмечено, что образ вообще, безотносительно к предмету, отображающим, его сущность, быть не может. ОН говорил, что образ в собственном смысле надо воспринимать, не все чувственные впечатления, а лишь те, которые становятся для субъекта предметами и объектами познания [9].

Сформированный образ предмета, не является его снимков, а его формирование захватывает длительное время, через отражение воспринимаемого предмета.

Проведенные исследования процессов познания, дают возможность определить уровни психического отражения: сенсорно-перцептивный, уровень представлений и вербально-логический (Н. Г. Салмина) [10].

Сенсорно-перцептивный уровень считается основным. Формируется он на первых этапах психического развития, и сохраняется на протяжении всей жизни. На разных возрастных этапах он изменяется, обогащается и трансформируется

У каждого человека, на протяжении жизни формируется индивидуальный сенсорно-перцептивный стиль, которые объединяет в целостную систему работу всех органов чувств (Б. Г. Ананьев). Она содержит сенсорные модальности, которые образуют 
функциональные органы, помогающие человеку на сенсорно-перцептивном уровне ориентироваться в изучении окружающего мира, где главную роль играет зрительный анализатор (А. А. Ухтомский).

На втором уровне, когда формируются представления, образное отражение выполняет ощущение и восприятие. Однако формированию представлений помогают целый круг психических процессов, где ведущее место занимает память и воображение. Полученный уровень представлений также является предметным. Он обеспечивает образованию в интеллекте человека когнитивных карт, наглядных моделей, образов эталонов, которые используются в различных видах деятельности.

Словесно-логический уровень познавательных процессов обеспечивает речемыслительный процесс. Он характеризует понятийное отражение и рациональное познание. Он позволяет человеку оперировать абстракциями, делать обобщения, которые зафиксированы в знаково-символических системах. Если учитывать, что самой развитой знаковой системой является язык, понятийное мышление расширяет круг знаков, математических, графических и др.

Сознательная деятельность человека регулируется всеми тремя уровнями психического отражения: сенсорно-перцептивным, представлений, вербально-логическим.

Они обеспечивают эффективность решения различных задач, с использованием логических действий, в соответствии с условиями задачи.

Эти положения дают возможность заключить, что образ, регулирующий познавательную деятельность, имеет сложное строение. Он многомерен и включает ряд уровней. По мнению Б. Г. Ананьева и С. Л. Рубинштейна, образное отражение действительности человеком носит по преимуществу зрительный характер.

Генетически исходным в формировании знаковых систем Л. С. Выготский считал жест. От него происходят первоначальные формы словесной речи, символическая игра и детский рисунок. Далее, Л. С. Выготский связывал жест, письмо и изобразительную деятельность, утверждая, что все они направлены на формирование письменной речи и представляют собой различные этапы на пути становления письма.

Созданная им методика исследования развития символической функции (знаковой), позволила дать объяснение переноса детьми значений с одного предмета на другой. У детей символический характер знака он видел в том, предмет используется как символ другого, и как заместитель других предметов (кубик заменяет чашку).

Знаково-символические средства используются в развитии речи, выполняя различные функции: индикативные, номинативные, регулятивные, сигнификативные. Их развитие имеет определенную последовательность: вначале образуется индикативная, затем коммуникативная, которая начинается с жестов. Номинативная и регулятивные функции формируются, когда ребенок уже понимает жесты и начинается общаться. Затем, формируется сигнификативная функция, при переходе к опосредованной форме познания через знаки [4].

В деятельности функция знаково-символических средств, обозначает три основных ее вида: коммуникативную, познавательную, замещающую.

Внутри коммуникативной и познавательной функций существуют и другие функции. В процессе коммуникации используется в виде индикативной, регулятивной, и эстетически оценочной функции. Познавательная функция используется для абстрагирования, с целью создания идеального или воображаемого предмета. Для этих функций используются такие виды знаково-символической деятельности, как кодирование 
и декодирование информации, моделирование ситуации, замещение и схематизация среды и других обстоятельств, надлежащих изучению.

Процесс замещения, предполагает замену известных предметов разнозначными объектами.

Замещение, подразумевает, как правило, имеется в виду замену каких-либо объектов или предметов равнозначными предметами. По логике, принцип замещения предполагает понимание логического заключения опирающегося на отношениях равенства или тождества.

Замещение - многозначный термин, в широком смысле включает многие виды деятельности с использованием знаково-символических средств. Таким образом, замещение применяется в процессе кодирования, схематизации, и в процессе моделирования. В любом случае замещение очень специфично, так как помогает подняться на высокий уровень логического мышления.

Действие кодирования как особый вид деятельности с применением знаковосимволических средств позволяет переводить реальность или текст описывающий реальность на знаково-символический язык, затем его и декодировать.

Кодирование применяется с целью последующего декодирования информации. Важное условие, при этом, то, что декодирующий, должен владеть ключом к декодированию информации. Ведь иногда мы сталкиваемся с ситуацией, когда теряется ключ, в результате чего, информация так и остается не декодированной, или не расшифрованной. Поэтому процесс декодирования направлен на распознание того, что закрыто конкретными знаками, но должен храниться и ключ к декодированию.

Процесс декодирования, направлен на распознание кодированной информации определенными знаками. Поэтому в декодировании важно распознать то, что было закодировано определенными знаками и символами [11].

Большое разнообразие существующих знаков и символов, которые используются в различных видах деятельности, создает определенные сложности в трактовке знаково-символических систем, определения их значения.

Естественно, детям дошкольного возраста еще недостаточно доступны пониманию в полной мере существующие видов знаково-символические средства. Однако имеющиеся исследования по использованию знаково-символических средств в обучении дошкольников, показывают, что в них заложены большие возможности для интеллектуального развития детей.

Исходя из раскрытых теоретических основ использования знаков и символов в познавательной деятельности в интеллектуальном развитии дошкольников, можно заключить, что дошкольный возраст является сензитивным для их применения при ознакомлении с окружающим миром.

Наш опыт показывает, в дошкольном возрасте дети усваивают широкий спектр знаний, об окружающем мире помощи условно-схематических изображений. Благодаря условно-схематичным изображениям дети умело сравнивают предметы, обобщают их основные отличительные особенности и отражают их условными знаками. Это ведение различных календарей наблюдения за объектами и явлениями в природе, фиксации последовательности действий, при выполнении определенных видов трудовой деятельности, передаче последовательности событий, заучивания стихотворений 
наизусть. В процессе обучения детей кодированию и декодированию информации у детей вырабатывается операционный стиль мышления, потребность самостоятельно формулировать задачу (А. Столяр) [11].

Большие возможности заложены в работе с детьми по применению метода «моделирования маленькими человечками», выявлены в исследовании А. Страунинг [12].

Сущность метода «моделирования маленькими человечками» (ММЧ), заключается в том, что детей учат представлять себе: все, что нас окружает, состоит из множества маленьких человечков. Человечки потому, что они могут думать, производить действия, вести себя по-разному. С их помощью можно моделировать любые жизненные ситуации. Моделированные ситуации использовались на познавательных занятиях, занятиях-экспериментах, игры-занятия по обучению грамоте, ознакомлению с окружающим и природой.

Проведенный нами эксперимент, с использованием знаково-символических систем в процессе обучения детей, свидетельствуют о том, что знаково-символические средства, таят в себе большие познавательные возможности в интеллектуальном развитии.

Для изучения возможностей в понимании детьми знаково-символических систем использовали такие методики как, «Неопределенная ситуация», «Классификация задач», «Непроизвольное запоминание», «Подбери картинку».

Сформированность знаково-символических способов познания выявляли с помощью методик: «Десять слов» (А. Р. Лурия), «Пиктограмма» (А. Р. Лурия), вербальный тест творческого мышления «Необычное использование» (в адаптации И. С. Авериной и Е. И. Щеблановой), краткий тест творческого мышления - фигурная форма (в адаптации И. С. Авериной и Е. И. Щеблановой), цветные прогрессивные матрицы Дж. Равена, «Подбери картинку».

В любом случае, после сбора информации, нужна качественная характеристика состояния развития интеллекта, постановка диагноза. Полученные данные использовали для определения путей обучения и формулировки рекомендаций.

\section{Литература}

1. Бурлачук Л. Ф., Морозов С. М. Словарь-справочник по психодиагностике. СанктПетербург, 1999. 528 с. Текст: непосредственный.

2. Ганзен В. А., Балин В. Д. Теория и методология психологического исследования: практическое руководство. Санкт-Петербург, 1991. 76 с. Текст: непосредственный.

3. Чуприкова Н. И. Умственное развитие. Принцип дифференциации. Санкт-Петербург: Питер, 2007. 448 с. Текст: непосредственный.

4. Выготский Л. С. Мышление и речь. Москва: Национальное образование, 2019. 430 с. Текст: непосредственный.

5. Гумбольт В. Фон - Избранные труды по языкознанию. Москва: Прогресс, 2000. 396 с. Текст: непосредственный.

6. Холодная М. А. Когнитивные стили в природе индивидуального ума. Москва, 2004. 384 с. Текст: непосредственный.

7. Кассирер 3. Избранное. Опыт о человеке. Москва, 1998. 784 с. Текст: непосредственный.

8. Логинова В. И. Саморукова П. Г. Дошкольная педагогика. Москва, 1988. 256 с. Текст: непосредственный.

9. Рубинштейн С. Л. Основы общей психологии. Санкт-Петербург, 2000. 712 с. Текст: непосредственный. 
10. Салмина Н. Г. Знак и символ в обучении. Москва: Изд-во Моск. ун-та, 1988. 288 с. Текст: непосредственный.

11. Столяр А. Могут ли дошкольники кодировать информацию // Дошкольное воспитание. 1989. № 6. С. 12-17. Текст: непосредственный.

12. Страунинг А. Моделирование маленькими человечками // Дошкольное воспитание. 1998. № 3. Текст: непосредственный.

Статья поступила в редакцию 02.10.2021; одобрена после рецензирования 13.10.2021; принята к публикащии 15.12.2021.

\title{
THE USE OF ICONIC AND SYMBOLIC MEANS IN PRESCHOOLERS INTELLECTUAL DEVELOPMENT
}

\author{
Nina V. Vlasova \\ Associate professor, Master of Pedagogy \\ Turan-Astana University \\ 29 Ykylas Dukenuly St., Nur-Sultan, 010013, Kazakhstan \\ E-mail: sher_nina147@mail.ru
}

The article presents the features of the intellectual development of preschool children, shows the role of the iconic and symbolic function of thinking in this process, the meaning of this function in the socialization of children. The characteristic of the system of iconicsymbolic means of thinking and the stages of its acquisition by preschoolers are given. Information encoding and decoding, situation modeling, environment and other circumstances substitution and schematization are used to fulfill these functions.

Some methods of identifying the levels of development of iconic-symbolic means of thinking (modeling ability), pedagogical technologies for the formation of modeling ability will be interesting for practicing preschool education teachers.

Keywords: intellectual development, intellectual development of preschool children, levels of development of iconic-symbolic means of thinking, modeling, socialization, the process of knowledge, mental levels: sensory-perceptual, level of representations and verbal-logical.

The article was submitted 02.10.2021; approved after reviewing 13.10.2021; accepted for publication 15.12.2021. 